\title{
Forensic Building: Deterioration and Defect in Concrete Structures
}

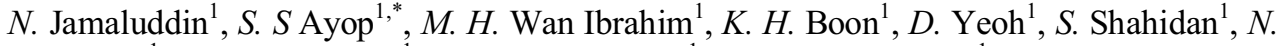 \\ Mohamad $^{1}, T$. N. Tuan Chik ${ }^{1}, N$. H. Abd. Ghafar ${ }^{1}, A$. H. Abdul Ghani ${ }^{1}$, and $S$. Shamrul- \\ Mar $^{1}$ \\ ${ }^{1}$ Jamilus Research Center, Faculty of Civil and Environmental Engineering, Universiti Tun Hussein \\ Onn Malaysia, 86400 Parit Raja, Johor, Malaysia
}

\begin{abstract}
Forensic building is needed to examine the affected building structure components to assess the structural integrity. This paper highlights some of the studies involved on affected concrete structures in various building types where the non-destructive test (NDT) and destructive tests. The structural integrity can be evaluated based on the extent of deterioration from the experimental results for instance the cause of the corrode reinforcements was due to inadequate concrete cover, whereas the failure of the concrete wall was due to structures' under design which leads to the collapse of the wall. The condition of the floor slab that experience vibration was assessed from the Laser Doppler Vibrator test (LDV). Based on the test results the peak acceleration of the particular floor slab is higher.
\end{abstract}

\section{Introduction}

A building is failing when the building loses its ability to perform its function. Building failure can be categorized as physical failure. Examples of physical failures are strength and performance failures due to the inability of the building to function as expected by the established acceptable limit suggested by standard codes. Building a structure carries with it an element of risk; thus, Building Codes establish a standard that structures must meet.

Structural failures can be associated with the choice of materials and shoddy workmanship. This paper highlights some of the assessments made on defect concrete structures and the process involved. The paper is not intended to discredit any parties, but to emphasis on the importance of engineering fundamental and judgement to avoid disastrous event.

Structures will fail when something goes wrong with the design that will affect its strength and stability. The understanding of material properties and behavior are crucial in the design process. Structural failure occurs due to the forces acting on it, either static or dynamic forces. The structures should not be loaded in a way that will cause a strength and system failure.

*Corresponding author: sallehs@uthm.edu.my 
Several tests have been conducted on several buildings. The tests were cover-meter test, concrete permeability test, carbonation test, chloride test and half cell potential test for building structure with exposed reinforcements. As for collapse concrete wall the tests involved were coring test and cover-meter test. In the case of vibrated concrete floor, the Laser Doppler Vibrometer test was performed.

\section{Structure failures and test results}

\subsection{Structure with exposed reinforcement}

Exposed reinforcements are amongst the severe conditions that could be observed from structures such as at columns and the underside of slab (Fig. 1). The spalling of the concrete parts and rusted steel reinforcement are clearly seen in these structures. These are the examples of distress failures in concrete structures which are caused by corrosion of the steel reinforcement.

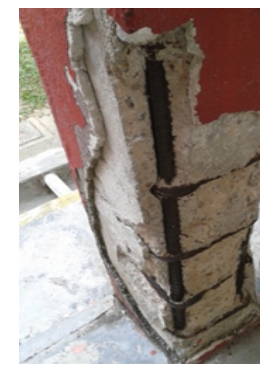

a) Column

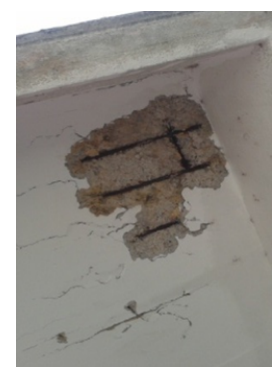

b) Slab

Fig. 1. Structures with exposed reinforcement

An alkaline environment of concrete provides steel reinforcement with corrosion protection [1]. However, the corrosion may take place when the alkalinity of the concrete is reduced or when the chloride concentration in concrete is increased to a certain level [2]. Corrosion of steel reinforcement may cause the concrete cracks and eventually concrete spalling. Rust occupies a greater volume than the steel in concrete, which creates stress in the concrete and eventually cause cracking and spalling of the concrete. Details of the corrosion mechanism have been discussed previously in [3]. In order to investigate the reason of the occurrence of such failure on the particular structures, few tests were conducted as follows;

\subsubsection{Cover-meter test}

The steel reinforcement can corrode in moist atmospheres, thus the low permeability concrete and adequate concrete cover will help to protect the embedded metals from corrosive materials. A cover-meter test was conducted on the affected structure in order determine the precise concrete cover depth and to determine the exact location of the rebars in concrete. Minimum concrete cover as stated in BS 8110-1-1997 [4], is between 20$50 \mathrm{~mm}$. Provision of correct cover depth as per the code recommendations will ensure minimum corrosion of the reinforcement bars. From the test results, the concrete cover was found be varies with the lowest cover is $8 \mathrm{~mm}$ which may indicate due shoddy construction. 


\subsubsection{Low permeability concrete}

Low permeability can also reduce the corrosion rate. The low permeability concrete could be attained by reducing the ratio of water to cementations materials. Permeability of concrete can be minimized by adopting low water-content ratio, ensuring proper compaction and curing of concrete. However the permeability concrete evaluation, rapid chloride permeability test was not conducted in this case.

\subsubsection{Carbonation test}

Carbonation is generally a slow process. The amount of carbonation is significantly increased in concrete with a high water-to-cement ratio, low cement content, short curing period, low strength, and highly permeable or porous paste. The carbonation test is carried out to determine the depth of concrete affected due to the combined attack of atmospheric carbon dioxide and moisture and causing a reduction in the level of alkalinity of concrete. Carbonation of concrete also lowers the amount of chloride ions needed to promote corrosion. This test was conducted in accordance with BS EN 14630:2006 [5] and the onsite carbonation tests were conducted in order to obtain real time results.

The test was carried out on the affected structure by spraying the indicator to pre-drilled holes at specific pre-determined locations. The pre-drilled holes using an $18 \mathrm{~mm}$ diameter drill bit with the total depth of $75 \mathrm{~mm}$ as requested by client including the concrete cover were performed. The affected depth is assessed using a solution of phenolphthalein indicator. Fig. 2 shows the carbonation test result. Carbonation test for the pre-drilled holes shows reddish-purple, which indicates that the $\mathrm{pH}$ is above 8.6 for un-carbonated condition of such structure. For the phenolphthalein solution which remains colorless, the $\mathrm{pH}$ of the concrete should be less than 8.6, suggesting carbonation or fully-carbonated.
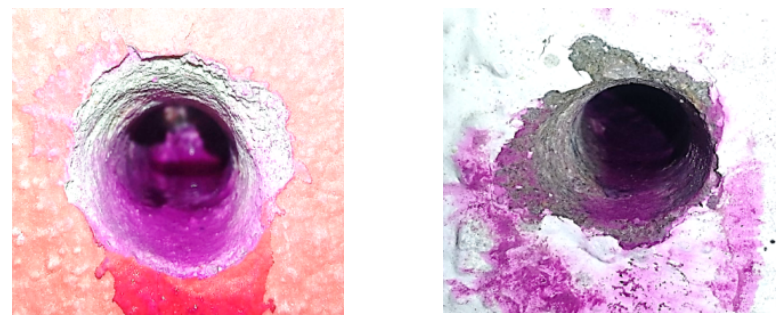

Fig. 2. Carbonation test for the pre-drilled holes

\subsubsection{Chloride test}

Chloride test was carried out in accordance with BS EN 14629:2007 [6]. The test was performed on the dusting powder obtained by drilling from the concrete structure from the specified point which was decided by the client. The concentration of chloride ions was determined from the powder collected at various depths in order to determine the likelihood of corrosion in the reinforcing steel. The concrete was drilled to a depth of $75 \mathrm{~mm}$ with the dusting powder collected after the first $25 \mathrm{~mm}$ depth as the first $25 \mathrm{~mm}$ is considered nonrepresentative. From the chloride test, the chloride contents were determined and compared with limiting values specified for the concrete to assess the risk of corrosion in concrete structure. From the chloride test results (Fig. 3), the chloride content was found to be less than $0.02 \%$, which indicates that the chloride content in current condition is accepted. It should be noted that the results represent the condition of the structure having an adequate thickness cover. 


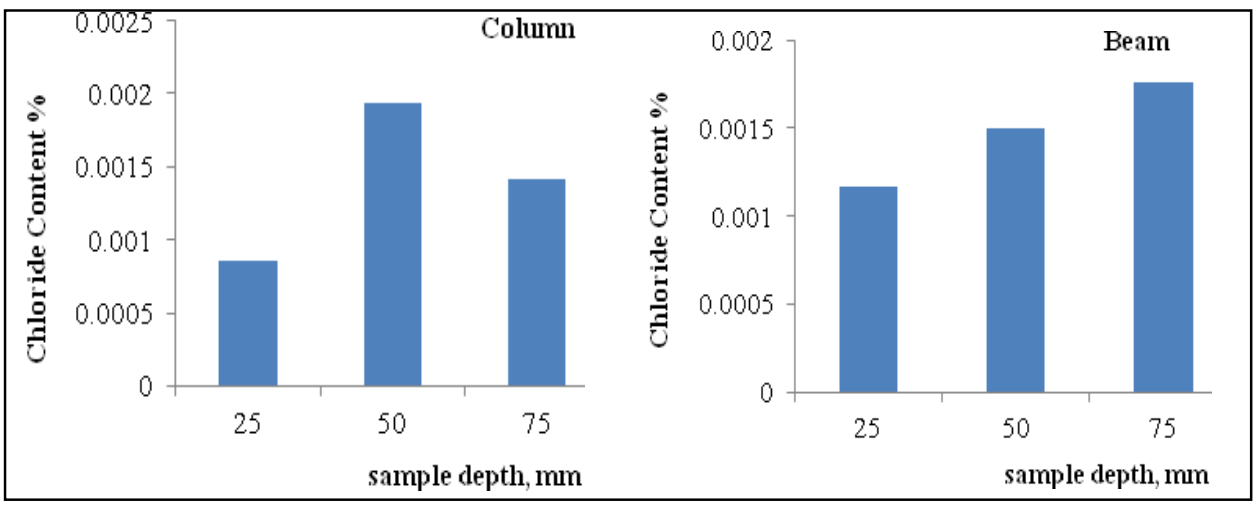

Fig. 3. Results of chloride test

\subsubsection{Half cell potential test}

Half cell corrosion detection technique was conducted to assess the steel condition in the concrete structure. This technique evaluates the risk of corrosion activity of steel in concrete. The test was conducted by referring to ASTM C876-15 [7] using copper sulphate electrode connected to a voltmeter. Measurements are taken from the pre-drawn grid at $200 \mathrm{~mm}$ distance. The possible potential electrode values were then compared with the criterion listed in Table 1.

Table 1. Criteria of corrosion according to ASTM C876-91

\begin{tabular}{|c|l|}
\hline $\begin{array}{c}\text { Open circuit potential (OCP) Values } \\
(\mathrm{mV} \text { vs. CSE) }\end{array}$ & \multicolumn{1}{|c|}{ Corrosion Condition } \\
\hline$<-500$ & Severe corrosion \\
\hline$<-350$ & High $(<90 \%$ of risk corrosion $)$ \\
\hline-350 to -200 & Intermediate corrosion risk \\
\hline$>-200$ & Low $(10 \%$ of risk corrosion $)$ \\
\hline
\end{tabular}

The results of the half cell potential test as shown in Table 2 indicate that the current condition of the reinforcements appeared to be losing its properties.

Table 2. Half cell corrosion results

\begin{tabular}{|l|l|}
\hline Location & Indicator \\
\hline Slab Soffit & $\begin{array}{l}\text { Intermediate corrosion risk with certain point has } \\
\text { high corrosion }(90 \% \text { risk) }\end{array}$ \\
\hline Beam & $\begin{array}{l}\text { Low risk corrosion with certain point has } \\
\text { intermediate risk. }\end{array}$ \\
\hline
\end{tabular}

\subsection{Collapse of concrete wall}

Another case that involves the structural failure is as shown in Fig.4; the collapsed concrete wall of an effluent tank. Visual inspection during the first visit observed the occurrence of honeycomb along the failure line of the wall concrete. 


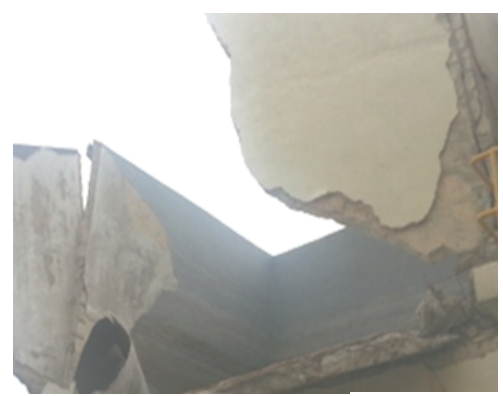

(a)

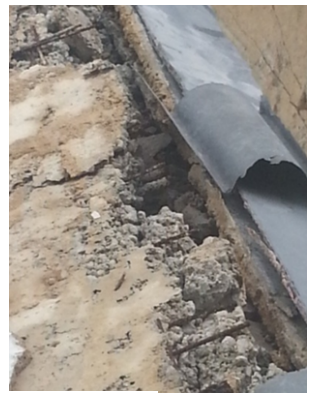

(b)

Fig. 4. Failure of effluent tank concrete wall

It is found that the main reasons for the occurrence of honeycomb are an improper consolidation of the concrete or from using stiff concrete. Junctions in the structure layout are typical spots where honey combs can be observed, which is due to jumbling of reinforcement of between the structures at one place in which special attention is required during concreting and vibrating. The high percentage of large aggregate size may prevent concrete to fill narrow spaces between the reinforcement rods. The presences of honeycomb in the concrete structure not only affect the load bearing capacity but also provide an easy access to water to finds reinforcement rods and start rusting and corrosion. Grout leakage along the structure perimeter.

\subsubsection{Coring test}

Coring test was conducted on the wall structure of the concrete tank. From the test, the strength of concrete is $27.43 \mathrm{~N} / \mathrm{mm}^{2}$. Considering the condition at the location, for safety reasons the coring sample was taken at the zone where honeycomb was not detected. Thus, due to the presence of a defect in the other zone, one can predict that the concrete strength will further reduce. From the finding, comparison was made in accordance to BS8007:1987 [8] and BS 8110-1-1997 [4] where it is stated that the minimum strength of $35 \mathrm{~N} / \mathrm{mm}^{2}$ is required for liquid retaining structure.

\subsubsection{Cover-meter test}

The cover-meter test was also carried out on the effluent tank to determine the concrete cover. Findings reveal the minimum concrete cover of $6 \mathrm{~mm}$ was found on the structure wall. For structure subjected to severe exposure condition, for concrete cover thickness it has different stipulation and protective measures. Relevant measures in terms of work environment and structure type should be taken into consideration. For the concrete wall tank, the minimum concrete cover of $40 \mathrm{~mm}$ should be provided.

\subsection{Vibrated floor slab}

Generally, vibration is not an issue for reinforced concrete floor systems due to inherent mass and stiffness of such systems. However, due to some reasons, the effects of vibration could be the main design issues that need to be addressed. Floor structures are designed for ultimate limit states and serviceability limit state criteria. Floor vibration generally makes people uneasy and creates fear of structural collapse and eventually affects people's sense of well being and ability to carry out tasks. Depending on a number of factors, the vibration 
can be annoying or worse for the people that are occupying the affected area. Floor vibration can be a greater problem, particularly for long-span floor structure. The main factor of the vibration problems is resonance, which occurs when a load is exerted on a floor at a particular frequency.

A study on a concrete floor slab was carried out on a structure building that has reported to have vibration problems. In this building case, the affected area is $6.5 \mathrm{~m} \times 10 \mathrm{~m}$ can be considered as the length of floor span.A preliminary inspection was conducted in the affected area and the followings have been observed:

i) Sense of discomfort for occupants- evident from occupant complaints.

ii) The out-of level condition of the floor- sagging floor

iii) Cracks in the floor slab (Fig. 5) and along the slab boundary

The first action taken in this situation is monitoring the crack development over a period of one week. All existing equipment on the floor space was not removed, but the area was closed for any activities. During the period, the cracks were observed to propagate from 0 to 1.5 inches. It stopped to propagate which indicate that the cracks have reached its equilibrium state.
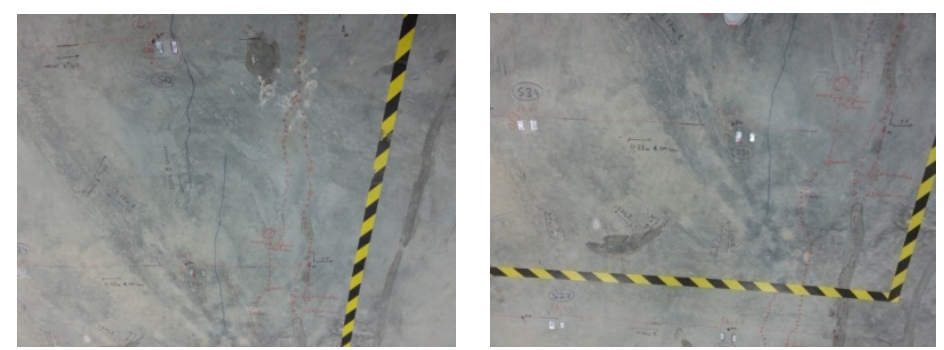

Fig. 5. Cracks on the affected floor slab

The test due to human activity (in this case; walking) was conducted to evaluate the vibration response. For the accepted floor slab response, the peak acceleration of the floor system should be less than or at least equal to the recommended acceleration for a particular occupation.

Peak acceleration is related to the natural frequency $(f n)$, the effective weight, and the inherent damping of the floor system. The natural frequency is a measurement of how the floor system will respond to the sources that can cause vibration, and is related to how the occupants will perceive such vibrations.

\subsubsection{Laser Doppler Vibrometer test}

Vibration waves were captured with Laser Doppler Vibrometer, LDV (Fig. 6) at a designated location on the affected floor area. From the test results, the peak vibration acceleration at the Location of L1 and L6 (Fig. 7) were among the higher as compared to other location with $0.0290 \mathrm{~m} / \mathrm{s}^{2}$ and $0.0219 \mathrm{~m} / \mathrm{s}^{2}$ respectively. The peak vibration acceleration for normal reinforced concrete floors as in previous studies is $0.007 \mathrm{~m} / \mathrm{s}^{2}$ whereas for concrete masonry load bearing system floor, the peak vibration acceleration is $0.00042 \mathrm{~m} / \mathrm{s}^{2}$ [9]. The results indicated that the peak acceleration for the floor is higher as results of people activity in this case walking. Therefore, it has been suggested that further investigation and analyses of natural frequencies, mass, damping for the floor need to be carried out in order to remedy the excessive vibration. Actions are necessary to improve the slab stiffness. 


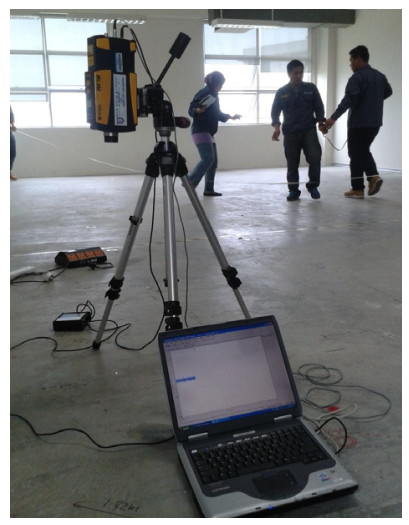

Fig. 6. The measurement was recorded based on human's footsteps
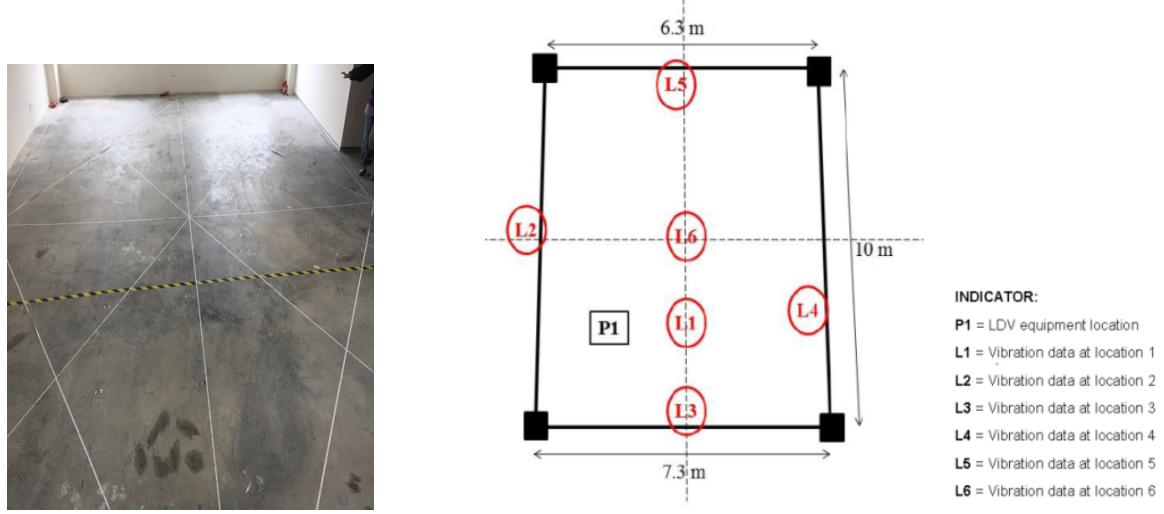

Fig. 7. Mapping for test locations

\section{Conclusions}

It is impossible to control the causes of possible failures in the structure. However, minimizing these causes will definitely reduce the amount and need for maintenance. With the case of a structure with exposed reinforcement, the principal reason leading to the current failures and defects in such building is potentially associated with deficiencies in the use of materials and construction quality. The corrosion of reinforcing steel bars is a critical concern which reduces significantly the life and durability of concrete structures. The corrosion of the reinforcement was expected due to shoddy construction as the concrete covers were found to vary with the lowest is $8 \mathrm{~mm}$.

As for the collapsing concrete wall, from the specific tests which requested by the client, the test results reveal that the structure was under design with the concrete cover and concrete strength are not adequate for the purpose of effluent tank.

In the case of vibrated floor slab, the mass and stiffness of the concrete structure need to be increased as an improvement on the vibration performance of the floors.

\section{References}

[1] Portland Cements Association, Types and causes of concrete deterioration, (2002), Retrieved on October 10, 2016 from http://www.cement.org/docs/default- 
source/fc_concrete_technology/durability/is536-types-and-causes-of-concretedeterioration.pdf?sfvrsn $=4$

[2] Portland Cements Association, Corrosion of embedded metals, Retrieved on October 10,2016 from http://www.cement.org/for-concrete-books-learning/concretetechnology/durability/corrosion-of-embedded-materials

[3] S.S. Ayop and J.J. Cairns, Critical study of corrosion damaged concrete structures, Int. J. of Integrated Engineering, 5(2), 43-50 (2013)

[4] BS 8110-1-1997, Structural use of concrete. Code of practice for design and construction, British Standard Institution, London (1997)

[5] BS EN 14630:2006, Products and systems for the protection and repair of concrete structures, Test Methods, Determination of Carbonation Depth in Hardened Concrete by the Phenolphthalein Method, British Standards Institute, London, (2006)

[6] BS EN 14629:2007, Products and systems for the protection and repair of concrete structures, Test Methods, Determination of Chloride Content in Hardened Concrete, British Standards Institute, London, (2007)

[7] ASTM C876-91, Standard test method for corrosion potentials of uncoated reinforcing steel in concrete, ASTM International, West Conshohocken, (1991)

[8] BS 8007:1987, Code of practice for design of concrete structures for retaining aqueous liquids, British Standards Institute, London, (1987)

[9] T.N. Tuan Chik, S. Yabi, N.A. Yusoff and M.I. Ghazali, Analysis of the effect of vibration from footfalls on office building, Proc. of the Int. Civil and Infrastructure Engineering Conf., Springer, 3-15 (2014) 